\title{
Learner-generated drawings by students with mathematical learning difficulties in finishing open number sentences
}

\author{
Mohammad Faizal Amir \\ Elementary School Teacher Education Department, Universitas Muhammadiyah Sidoarjo, East Java, \\ Indonesia \\ *Correspondence: faizal.amir@umsida.ac.id \\ (C) The Author 2022
}

\begin{abstract}
Although MLD students do not have good mathematical performance in completing addition and subtraction operations of integers, MLD students have suggestive ideas in the form of drawings produced in solving open number sentences questions. This study aims to classify the types and identify changes in the drawing produced by MLD students in solving open number sentences questions. This research method is qualitative with a micro generic study approach to understand students' thinking individually and explore drawing changes in solving open number sentences questions between sessions. The research subjects were 2 out of 20 MLD grade 5 elementary school students who produced the most varied drawings in solving open number sentences questions. Data collection techniques used are giving questions and interviews. The results showed that MLD students produced: discrete object drawings by focusing on the cardinality of the quantity of a number; transitions from objects to the number line by focusing on the magnitude of numbers; partitioning the number line using magnitude reasoning; number sentences; and others using verbal reasoning. Changes in the drawings produced by MLD students between sessions indicate the development of students' understanding towards a better direction in interpreting symbolic representations to visual representations. The results of this study contribute to the theory that although MLD students have low mathematical performance. However, MLD students can produce variations and changes in drawings with rich mathematical idea information representing integer operations.
\end{abstract}

Keywords: integers; learner-generated drawings; MLD students; open number sentences

Received: 22 November 2021 | Revised: 30 November 2021

Accepted: 17 December 2021 | Published: 6 January 2022 


\section{Introduction}

Mathematical development does not occur naturally in every child. Those who experience severe and persistent problems have mathematical learning difficulties (MLD) (Huijsmans et al., 2021). Students in the MLD category have less specific mathematical abilities and weak cognitive processes in solving math problems (Hanich et al., 2001; Karagiannakis et al., 2014). MLD students also have weak mathematical performance and experience difficulties solving problems on integer operations (Fuadiah et al., 2019). MLD students understand conventional integers in terms of quantity and symbolic notation. In addition, MLD students have difficulty conceptualizing and manipulating negative numbers (Lewis et al., 2020). Bryant et al. (2020) revealed that MLD students often ignore positive or negative signs in integers.

MLD students at the elementary school level also had difficulty in solving questions about addition and subtraction operations on integers (Bryant et al., 2020; Lewis et al., 2020; Shanty, 2016). This is based on the lack of understanding of MLD students about the use of the sign (-), which means negative and the subtraction operation (Bofferding, 2014; Cetin, 2019). In some cases, elementary school students found it difficult because they considered the minus sign subtraction and did not recognize the negative sign. Therefore, these students cannot solve 3-5 because they think that small numbers cannot be reduced by large numbers (Bishop et al., 2014). In the case of other integer operations, MLD students interpret negative numbers as equal positive numbers as if the two values are equivalent and make integer reasoning connections based on the concept of subtraction (Bishop et al., 2018; Bofferding, 2014; Karagiannakis et al., 2014).

Although MLD students do not have good mathematical performance in addition and subtraction operations of integers (Lewis et al., 2020), they can have a good mathematical performance development on the visualization of the resulting drawing (learner-generated drawings) (Schmidgall et al., 2019). This also happens to students who have difficulty operating integers (Wessman-Enzinger, 2019). MLD students provide better problem solving by representing the meaning of operations through learner-generated drawings rather than solving problems only in the form of symbols or writing (Hoogland et al., 2018). This shows that the mathematical performance of MLD students cannot only be seen from the achievement of true or false answers but also knowledge information in the form of representations of mathematical ideas with learner-generated drawings (Gulkilik et al., 2020; Van Meter \& Garner, 2005). This includes making drawing intuitions in operating integers (Saxe et al., 2013). This is because the conceptual nature of the operation of addition and subtraction of integers cannot be modeled with physical objects but with the representation of numbers through drawings (Stephan \& Akyuz, 2015).

Open number sentences contain variables, but the correct value is unknown so that the statement can be true or false (Bishop et al., 2018). In other words, to make an open number sentence true, the variable must be replaced with the correct value. Through open number sentences, students are more flexible in using their thinking when operating integers (Carvalho $\&$ Ponte, 2016). In addition, elementary school students understand integers using productive means of their reasoning at the early stage rather than the school-based teaching they get (Lamb 
et al., 2016). Giving open number sentences in addition and subtraction operations of integers can be an insightful assessment tool to describe and understand students' thinking and learning (Wessman-Enzinger \& Mooney, 2019).

Although MLD students have poor mathematical performance, they may have certain drawings generated when solving open number sentences problems. Learner-generated drawings of MLD students are more urgent to identify than simply knowing students' correct or incorrect answers on the topic of addition and subtraction operations on integers. Thus, identifying the type of learner-generated drawings will provide representative information in the form of the location of the wrong mathematical ideas and the forms of difficulties MLD students face in a more representative manner. In addition to providing information on the classification of drawing types, the open number sentences questions presented in several completion sessions can provide information on changing drawing types. This change has important information in the form of the development of cognitive ideas towards the addition and subtraction operations of integers in a better direction (Wessman-Enzinger \& Mooney, 2019).

Therefore, this study was conducted to examine and explore in-depth information about the types and changes in learner-generated drawings of MLD students in completing open number sentences in several sessions on addition and subtraction operations on integers. This research contributes to the science of mathematics education by providing an overview of the types and changes in mathematical ideas in learner-generated drawings for MLD students. It has implications for evaluation and a more appropriate form of teaching stimulation for MLD students so that difficulties and obstacles in forming mathematical ideas for MLD students can be minimized in operating integers.

\section{Methods}

This research is part of an umbrella scheme research, a teaching experiment through various tasks. The variety of tasks given in the form of contextual problems, temperature models, and open number sentences is to identify changes in the learner-generated drawings of MLD students without intervention. Learner-generated drawings of MLD students are a natural result of students after being trained in teaching in group tasks of contextual problems. At the time of the task of individual open number sentences, MLD students were not trained to draw drawings. This is done to get a natural drawing and drawing change.

This study uses a qualitative method to classify and identify changes in the learnergenerated drawings of MLD students through a micro generic study approach. (Cresswell, 2012). Microgenetic studies carry out observations made over a certain period and emphasize the rate of phenomena to conclude the processes that give rise to aspects of change (Siegler \& Crowley, 1991). In this study, the micro genetic study as an approach was carried out for three weeks by giving individual open number sentences questions.

Data collection techniques used open number sentences and semi-open interviews. Open number sentences on the topic of integer addition and subtraction operations (See Table 1) are done individually. Then, this question was given in three research sessions (first, second, and 
third sessions), which were carried out for three weeks with a distance of one week between each session. The questions given in each session consist of 10 questions and have the same type of questions. This is done to categorize and change MLD students' learner-generated drawings consistently.

Table 1. Open number sentences questions given in each session

\begin{tabular}{cccc}
\hline No. & $\begin{array}{c}\text { Open Number } \\
\text { Sentences } \\
\mathbf{1}^{\text {st }} \text { Session }\end{array}$ & $\begin{array}{c}\text { Open Number } \\
\text { Sentences } \\
\mathbf{2}^{\text {nd }} \text { Session }\end{array}$ & $\begin{array}{c}\text { Open Number } \\
\text { Sentences } \\
\mathbf{3}^{\text {rd }} \text { Session }\end{array}$ \\
\hline 1 & $-10+17=\square$ & $-12+16=\square$ & $-11+18=\square$ \\
2 & $\square+-9=-16$ & $\square+-3=-7$ & $\square+-3=-5$ \\
3 & $1-\square=3$ & $2-\square=5$ & $3-\square=8$ \\
4 & $2--3=\square$ & $3--1=\square$ & $4--2=\square$ \\
5 & $-18+-17=\square$ & $-15+-14=\square$ & $-16+-12=\square$ \\
6 & $-4+\square=10$ & $-5+\square=12$ & $-4+\square=10$ \\
7 & $-5-4=\square$ & $-3-6=\square$ & $-5-4=\square$ \\
8 & $\square--1=6$ & $\square--4=8$ & $\square--1=6$ \\
9 & $-12-\square=-13$ & $-15-\square=-18$ & $-12-\square=-13$ \\
10 & $9+-5=\square$ & $6+-4=\square$ & $9+-5=\square$ \\
\hline
\end{tabular}

The research participants were 20 MLD students in class V of SDN Kalitengah 2 Tanggulangin (a school in the suburbs of Sidoarjo). The study participants had no previous instructional experience with integer operations. The determination of MLD students emphasizes three categories: (1) severity, which is the level of performance on standard math tasks, (2) persistence, which is the slow duration of math problems; and (3) specificity, which means that there is no comorbid learning or mathematical behavior disability (Huijsmans et al., 2021; Luit, 2019). In this study, the three categories were covered by the low results of solving open number sentences questions below the minimum completeness criteria of 70 (grade $<70$ ).

The research subjects were two of 20 MLD students determined by purposive sampling. The purposive criteria in this study were the drawings of students who varied the most during individual sessions in solving open number sentences so that students 1 (S1) and student 2 (S2) were obtained. During the individual open number sentences session, the subject wrote the answer on paper. The subject was not provided with manipulative objects (only writing tools were given).

Data analysis involved data reduction, presentation, and conclusion (Miles et al., 2014). Data reduction was carried out by eliminating data that did not match the type and changes in learner-generated drawings by MLD students. The presentation of the data is done by displaying learner-generated drawings and a table of drawing changes in each session of open number sentences. Conclusions were drawn by classifying the similarities in the types of drawings and the differences in the learner-generated drawings of MLD students in each open number sentence session. 


\section{Results}

This section describes the results of the classification and drawing changes produced by MLD students (S1 and S2) in each open number problem-solving session. S1 and S2 are the selected MLD subjects because they score below 70. Still, they produce the most varied drawings in the first, second, and third sessions of solving individual open number questions.

\section{Classification of types of learner-generated drawings for MLD students}

\section{Discrete objects}

The discrete object drawings produced by these students have the characteristics of adding or removing objects. There are two types of discrete objects: objects in single and double sets. The first type indicates objects removed or added in a set. Meanwhile, the second type is characterized by two sets to compare or state different parts of the whole object (WessmanEnzinger, 2019).

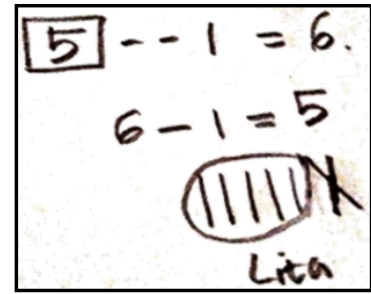

(a)

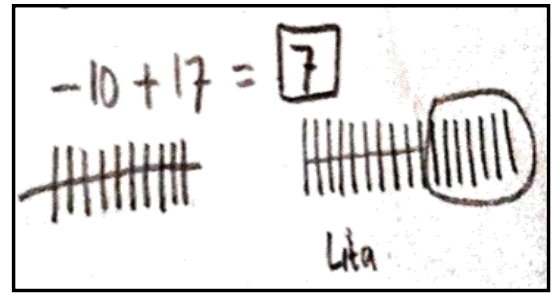

(b)

Figure 1. (a) Single discrete objects generated by S2 and (b) Multiple discrete objects generated by $\mathrm{S} 2$

When faced with the problem $\square--1=6, \mathrm{~S} 2$ solved as shown in Figure 1.(a) and stated "six lines on the right side then cross out one line and will produce a positive five because the remaining five lines on the right side." In this case, S2 solved the problem correctly. S2 draws a set of rows for positive numbers then removes negative numbers by crossing them from the set of positive numbers.

In the next problem, which is $-10+17=\square, \mathrm{S} 2$ solved as shown in Figure 1.(b) and stated, "draw ten lines on the left and seventeen on the right, the left is negative, and the right is positive. Then remove the negative by crossing out the right and left sides by ten lines. The result is positive seven". In this case, S2 solves the problem with the correct solution, drawing the positive number object using the set of rows on the right and the negative number object on the left. Next, S2 removes the set of negatives on the left side by crossing out the left and right sides as many as negative number objects. As a result, there are seven remaining rows to represent the solution, and the solution is positive because it is on the right-hand side.

The S2 statement corresponds to the types of discrete object drawings that students produce by adding or removing objects from the collection of objects. When generating drawings of discrete objects, students focus on the cardinality of the quantity. The cardinality of a quantity represents several objects in the problem of negative or positive numbers. 


\section{The transition from objects to number lines}

This drawing has the type of movement in the direction of the object without producing lines, scales, or line segments. When there is a problem $-5-4=\square, S 2$ solved the problem as shown in Figure 2.(a) and stated, "the number from negative five goes back four steps and stops at negative one." S2 solves the problem with the wrong solution, writes a sequence of numbers with a backward movement of four steps, and stops at minus one.

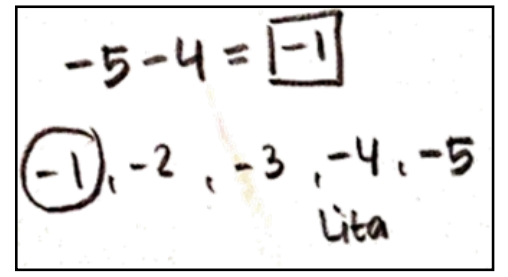

(a)

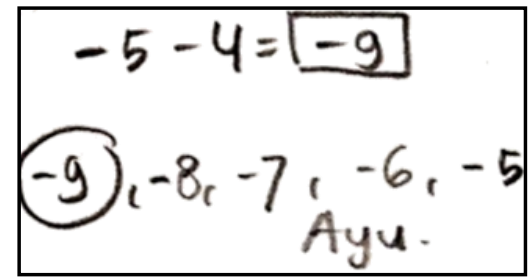

(b)

Figure 2. (a) Transition of discrete objects to lines of number by $S 2$ and (b) Transition from objects to lines of number drawn by $\mathrm{S} 1$

S1 also solved this problem using a number sequence as shown in Figure 2.(b) and stated, "the number from negative five goes back four steps and stops at minus nine." In this case, S1 solves the problem with the correct solution, writes a sequence of numbers with a backward movement of four steps, and stops at minus nine.

In this problem, S1 and S2 solve the problem by producing a drawing of the type of transition from objects to number lines according to the type, using a number sequence, and directing the number forward or backward even though it does not produce a number line. In addition, students also state the sequence of numbers by focusing on the magnitude of a number.

\section{Continuous number lines}

In this type of drawing, students pay attention to line segments and highlight distances. When there is a problem $-4+\square=10, \mathrm{~S} 2$ is described as shown in Figure 3.(a), and stated "counting with number lines then minus four on the left and ten on the right, the distance from minus four to ten is fourteen." In this case, S2 solves the problem with the correct solution, draws number lines then places positive numbers located right side and negative numbers located left side. In addition, $\mathrm{S} 2$ also calculates the distance from minus four to ten.

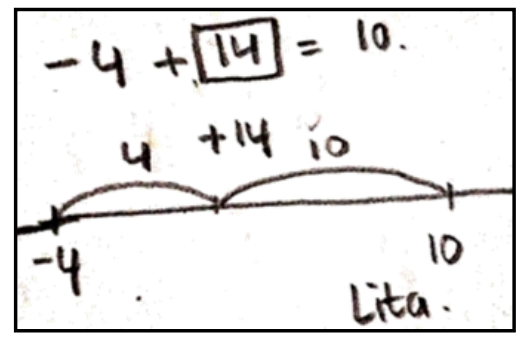

(a)

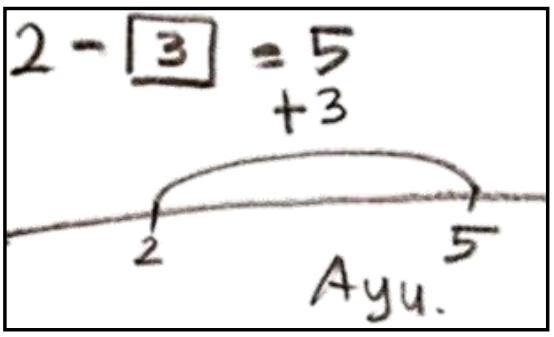

(b)

Figure 3. (a) Continuous number lines drawn by $\mathrm{S} 2$ and (b) Continuous number lines drawn by $\mathrm{S} 1$ 
S1 also solved the problem $2-\square=5$ using an empty number line as shown in Figure 3.(b) and stated, "draw a number line then five is on the right, and two are on the left, counting the jumps there are three so the result is positive three." In this case, S1 solves the problem with the wrong solution, namely by using number lines and stating the same strategy by placing five or positive numbers located right side and two on the left and then calculating the distance by three. In this case, the main factor in the $\mathrm{S} 1$ error is that it only highlights the number lines distance but does not consider the subtraction operation. S1 stated, " to produce five, then two is added by three on the number line."

This type of learner-generated drawings remains the category of student-generated drawings even though the solutions found are wrong. In this problem, S1 and S2 solve the problem by drawing the empty number line according to the type, placing positive numbers located right side and negative numbers located left side, or paying attention to line segments and highlighting distances. In this case, students produce an empty number line drawing using magnitude reasoning that compares a number.

\section{Number sentences}

This drawing has a type of rewrite or rewrites problem vertically and horizontally. When there is a problem of $-4+\square=10, \mathrm{~S} 1$ used horizontal sentences as shown in Figure 4.(a) and stated, "writing sideways ten minus four equals six." In this case, S1 solves the problem by rewriting the number horizontally, but the resulting solution is wrong. This happens because S1 does not highlight the addition sign (+) on the question. S1 expresses, "a number with a large value (10) will always be on the left side as a number that can be subtracted from a number with a small value (4)."

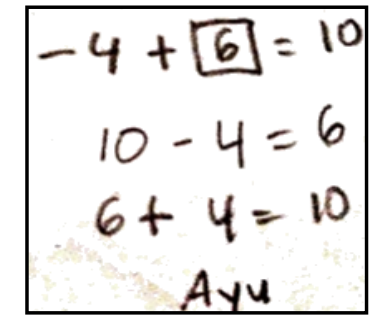

(a)

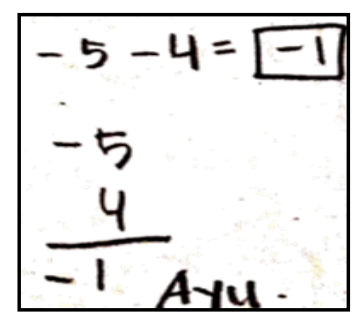

(b)

Figure 4. (a) Horizontal sentences made by $\mathrm{S} 1$ and (b) Vertical sentences made by $\mathrm{S} 1$

Another problem $-5-4=\square$ using vertical sentences as shown in Figure 4.(b) and stating "down negative five minus four and the result is a negative one." In this case, S1 solves the problem by rewriting the numbers in the problems that are arranged downwards or vertically, but the resulting solution is wrong. This is because S1 expresses "only highlights the sign of negative five or negative one only, without considering the subtraction operation." In this problem, S1 solves the problem by producing drawings of horizontal sentences and vertical sentences according to the type, namely rewriting or rewriting the problem both vertically and horizontally. 


\section{Other}

This drawing only answers the results, highlights the sign, and only understands the problem with verbal reasoning. When there is a problem $1-\square=3, \mathrm{~S} 1$ used another type of drawing (cross mark) as shown in Figure 5.(a) and stated, "one minus three, the question is probably wrong and crosses it." In this case, S1 solves the problem by crossing the numbers in the problem because it considers the problem an error and does not find the right solution to produce a cross draw.

There is also another problem, $9+-5=\square, \mathrm{S} 1$ used another drawing (emphasis marks) as shown in Figure 5.(b) and stated, "nine plus negative five becomes nine minus five, and the result is four." S1 solves the problem by ignoring it by changing the double sign (plus and negative) to minus to make the calculation easier, and the resulting solution S1 is correct. S1 solves the problem by producing other drawings (crosses and emphasis marks) according to the type, namely only answering the results, highlighting the marks, only understanding problems with verbal reasoning.

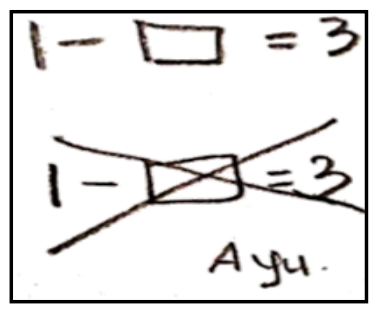

(a)

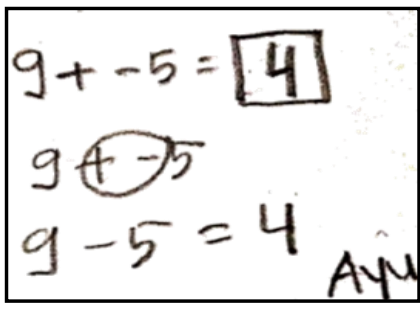

(b)

Figure 5. (a) Blank made by $\mathrm{S} 1$ and (b) Sign emphasis made by $\mathrm{S} 1$

Students ignore the sign or change the sign and produce across because they cannot solve the problem. This can happen if viewed from the students' representation of the minus sign as a subtraction, negative and opposite. Students perceive the negative sign (-) as a subtraction in this problem. There is also another problem that is solved by emphasizing the sign by ignoring the negative sign. However, ignoring the signs does not mean that students are unproductive in producing drawings. It makes mathematical sense.

\section{The change of learner-generated drawings on MLD students in each session}

S1 and S2 produce different drawings in each session of solving open number sentences. Changes in learner-generated drawings for S1 and S2 are explained through the percentage of learner-generated drawings for each session. Changes in S1 and S2 learner-generated drawings in each session are in Table 2 and Table 3.

\section{Learner-generated drawings $S 1$ in each session}

In Table 2, S1 consistently produces horizontal or vertical sentences, emphasizing plus, minus, or negative signs in each session. S1 does not produce objects in a single set, number lines, and answer in the box only in all sessions. Meanwhile, the objects in a double set, number sequence, and empty number lines were consistently used in session two and three, but this experienced a decrease in blanks. 
Table 2. Learner-generated drawings changes by $\mathrm{S} 1$ in each session

\begin{tabular}{|c|c|c|c|}
\hline Drawing Type & $\begin{array}{l}\text { Individual } \\
1^{\text {st }} \text { Session } \\
(\mathrm{n}=10) \\
\end{array}$ & $\begin{array}{l}\text { Individual } \\
2^{\text {nd }} \text { Session } \\
(\mathrm{n}=\mathbf{1 0})\end{array}$ & $\begin{array}{l}\text { Individual } \\
3^{\text {rd }} \text { Session } \\
(\mathrm{n}=10)\end{array}$ \\
\hline Objects in single set & $0(0 \%)$ & $0(0 \%)$ & $0(0 \%)$ \\
\hline Objects in double set & $0(0 \%)$ & $\begin{array}{l}1(10 \%) \\
\text { Correct }\end{array}$ & $\begin{array}{l}1(10 \%) \\
\text { Correct } \\
\end{array}$ \\
\hline Number sequence & $0(0 \%)$ & $\begin{array}{l}1(10 \%) \\
\text { Correct }\end{array}$ & $\begin{array}{l}3(30 \%) \\
\text { All Correct }\end{array}$ \\
\hline Empty number line & $0(0 \%)$ & $\begin{array}{l}2(20 \%) \\
\text { Correct } 1 \\
\text { incorrect } 1 \\
\end{array}$ & $\begin{array}{l}1(10 \%) \\
\text { Correct }\end{array}$ \\
\hline Number line & $0(0 \%)$ & $0(0 \%)$ & $0(0 \%)$ \\
\hline Horizontal sentences & $\begin{array}{l}2(20 \%) \\
\text { Correct } 1 \\
\text { incorrect } 1\end{array}$ & $\begin{array}{l}1(10 \%) \\
\text { Correct }\end{array}$ & $\begin{array}{l}1(10 \%) \\
\text { Correct }\end{array}$ \\
\hline Vertical sentences & $\begin{array}{l}3(30 \%) \\
\text { Correct } 2 \\
\text { Incorrect } 1 \\
\end{array}$ & $\begin{array}{l}2(20 \%) \\
\text { All Correct }\end{array}$ & $\begin{array}{l}2(20 \%) \\
\text { All Correct }\end{array}$ \\
\hline Answer in the box only & $0(0 \%)$ & $0(0 \%)$ & $0(0 \%)$ \\
\hline $\begin{array}{l}\text { Emphasis on the plus, minus, or } \\
\text { negative sign }\end{array}$ & $\begin{array}{l}1(10 \%) \\
\text { Correct }\end{array}$ & $\begin{array}{l}1(10 \%) \\
\text { Correct }\end{array}$ & $\begin{array}{l}2(20 \%) \\
\text { All Correct }\end{array}$ \\
\hline Blank & $\begin{array}{l}4(40 \%) \\
\text { All incorrect }\end{array}$ & $\begin{array}{l}2(20 \%) \\
\text { All incorrect }\end{array}$ & $0(0 \%)$ \\
\hline
\end{tabular}

The horizontal sentences generated by S1 obtained incorrect and correct solutions, but the incorrect solutions decreased in each session. Likewise, the vertical sentences and the empty number line generated by $\mathrm{S} 1$ obtained incorrect and correct solutions, but the incorrect solutions decreased each session. Meanwhile, the objects in double set, number sequence, suppression of the plus, minus, or negative signs produced by S1 get the correct solution.

\section{Learner-generated drawings $S 2$ in each session}

In Table 3, S2 consistently produces double sets of objects, number sequence, and empty number lines in each session. S1 does not produce number line, blank and answer in the box only in all sessions. At the same time, vertical sentences, emphasis on the plus, minus, or negative sign were consistently generated in session two and three. There was also an experience of a decrease in a objects in single set generated in session one and horizontal sentences generated in session two.

Table 3. Learner-generated drawings changes by $\mathrm{S} 2$ in each session

\begin{tabular}{llll}
\hline Drawing Type & $\begin{array}{l}\text { Individual } \\
\mathbf{1}^{\text {st Session }} \\
(\mathbf{n = 1 0})\end{array}$ & $\begin{array}{l}\text { Individual } \\
\mathbf{2}^{\text {nd }} \text { Session } \\
(\mathbf{n = 1 0})\end{array}$ & $\begin{array}{l}\text { Individual } \\
\text { Session three } \\
(\mathbf{n = 1 0})\end{array}$ \\
\hline Objects in single set & $\begin{array}{l}2(20 \%) \\
\text { Correct 1 } \\
\text { Incorrect 1 }\end{array}$ & $0(0 \%)$ & $0(0 \%)$ \\
\hline Objects in double set & $3(30 \%)$ & $2(20 \%)$ & $1(10 \%)$ \\
\hline
\end{tabular}




\begin{tabular}{|c|c|c|c|}
\hline Drawing Type & $\begin{array}{l}\text { Individual } \\
1^{\text {st }} \text { Session } \\
(\mathrm{n}=10)\end{array}$ & $\begin{array}{l}\text { Individual } \\
2^{\text {nd }} \text { Session } \\
(\mathrm{n}=10)\end{array}$ & $\begin{array}{l}\text { Individual } \\
\text { Session three } \\
(\mathbf{n}=10)\end{array}$ \\
\hline & $\begin{array}{l}\text { Correct } 2 \\
\text { Incorrect } 1\end{array}$ & $\begin{array}{l}\text { Correct } 1 \\
\text { Incorrect } 1\end{array}$ & Correct \\
\hline Number sequence & $\begin{array}{l}2(20 \%) \\
\text { All Correct }\end{array}$ & $\begin{array}{l}2(20 \%) \\
\text { All Correct }\end{array}$ & $\begin{array}{l}2(20 \%) \\
\text { All Correct }\end{array}$ \\
\hline Empty number line & $\begin{array}{l}3(30 \%) \\
\text { Correct } 2 \\
\text { Incorrect } 1\end{array}$ & $\begin{array}{l}3(30 \%) \\
\text { All Correct }\end{array}$ & $\begin{array}{l}5(50 \%) \\
\text { All Correct }\end{array}$ \\
\hline Number line & $0(0 \%)$ & $0(0 \%)$ & $0(0 \%)$ \\
\hline Horizontal sentences & $0(0 \%)$ & $\begin{array}{l}1(10 \%) \\
\text { Incorrect }\end{array}$ & $0(0 \%)$ \\
\hline Vertical sentences & $0(0 \%)$ & $\begin{array}{l}1(10 \%) \\
\text { Correct }\end{array}$ & $\begin{array}{l}1(10 \%) \\
\text { Correct }\end{array}$ \\
\hline Answer in the box only & $0(0 \%)$ & $0(0 \%)$ & $0(0 \%)$ \\
\hline $\begin{array}{l}\text { Emphasis on the plus, minus, or } \\
\text { negative sign }\end{array}$ & $0(0 \%)$ & $\begin{array}{l}1(10 \%) \\
\text { Correct }\end{array}$ & $\begin{array}{l}1(10 \%) \\
\text { Correct }\end{array}$ \\
\hline Blank & $0(0 \%)$ & $0(0 \%)$ & $0(0 \%)$ \\
\hline
\end{tabular}

The objects in single set generated only in session one got the wrong and right solutions. While the objects in double set generated by S1 obtained incorrect and correct solutions, the correct solution decreased in each session, but the wrong solution decreased in session three. The number sequence and empty number line generated by S1 obtained the correct solution in each session. Likewise, the vertical sentences and the emphasis on the plus, minus, or negative signs produced by $\mathrm{S} 1$ obtained the correct answer in session two and session three. On the other hand, the solution to the horizontal sentences generated in the second session is wrong.

\section{Discussion}

The synthesis of the classification of learner-generated drawings for MLD students is presented in Table 4. Learner-generated drawings for MLD students consist of objects in single or double set objects, number sequence, lines of empty number, vertical and horizontal sentences, blank, answer in the box only, and emphasizing the plus, minus, or negative signs. In addition, changes in the learner-generated drawings of MLD students between sessions are discussed in this section.

Table 4. Various types of learner-generated drawings by MLD students

\begin{tabular}{lc}
\hline \multicolumn{1}{c}{ Drawing Type } & Drawing Example \\
\hline \multicolumn{1}{c}{ Discrete Objects } & {$[5--1=6$.} \\
Objects in a single set: A set of discrete objects are removed or & $6-1=5$ \\
added from an existing set. &
\end{tabular}




\begin{tabular}{lc}
\multicolumn{1}{c}{ Drawing Type } & Drawing Example \\
\hline \multicolumn{1}{c}{ The Objects to Number Lines Transition } \\
Lumber sequence: There are many objects listed or an ordered \\
number.
\end{tabular}

Learner-generated drawings of MLD students in addition and subtraction of integers illustrate how students solve open number sentences according to their perspective or thinking naturally (Bishop et al., 2014; Bofferding \& Wessman-Enzinger, 2017; Van Meter \& Garner, 2005). This is because the research was conducted before students got the topic about integers, and in the process of producing learner-generated drawings, students were carried out without using manipulative models or explicit instructional models.

MLD students produce certain drawings with different frequencies. For example, S1 uses vertical sentences more often in each session, while S2 uses empty number lines. This difference is due to students' initial knowledge about completing addition and subtraction operations on integers (Bishop et al., 2018). Meanwhile, differences in student-generated drawings may indeed occur in solving questions in open number sentences which frees up the production of student drawings according to students' completion strategies (WessmanEnzinger, 2019).

Each individual produces drawings compared to the others. This suggests that children do not consider integers in the same way. MLD students are freed to produce and construct their drawings as instructional models (Lewis et al., 2020; Wessman-Enzinger, 2019). S1 showed more variety in producing drawings in session two and session three compared to session one 
in solving the problem of open number sentences. However, students can produce most of the drawings in one type. The process shows students' consistency in thinking about integers and generating drawing representations (Bishop et al., 2014; Schmidgall et al., 2019). This is shown by $\mathrm{S} 2$, who produces drawings in each open number sentence problem solving using number sequence in session one to session two.

Learner-generated drawings of MLD students at the elementary school level on the topic of addition and subtraction operations on integers can complement the other created drawings because they are explicitly connected to the thinking of elementary school students (Lewis et al., 2020; Wessman-Enzinger \& Mooney, 2014). The findings of this drawing by S1 show that vertical sentencess are marked with emphasis on the $\mathrm{S} 2$ also produces drawings of objects in a single set marked with a horizontal sentences. In addition, S2 draws an empty number line drawn with horizontal sentences.

Changes in the learner-generated drawings of MLD students showed some changes in each session. S1 in session one produced a lot of blanks, which means it did not produce any drawings and could not solve the problem of open number sentences, and produced horizontal and vertical sentences with incorrect results. In session two, S1 started to produce empty number lines, emphasis on the plus, minus, or negative sign for types of questions that produced blanks, but still with wrong results. Likewise, S1 no longer produces blanks in session three, and the results given are correct. In session three, S1 produces drawings with the types of number sequence, horizontal sentences, vertical sentences, and emphasis on the plus, minus, or negative sign.

$\mathrm{S} 2$ has produced discrete objects in single or double sets and number sequence in session one, but the results are still wrong. In session two, S2 uses different types of drawings on several types of questions. S2 solves problems with horizontal or vertical sentences, emphasizing number operation signs, with correct results. In session three, S2 did not produce new drawings for each type of question. Learner-generated drawings in session three were relatively the same as those in session two. Because illustrating the production and development of drawings take time. The use of drawings and their changes represent a potential perspective on drawing development. This shows that students can develop and create different models according to the development of learning (Wessman-Enzinger, 2019).

Thus, from the description above, MLD students solve open number sentences in addition and subtraction operations with integers and changes in session time, as seen from the development of students' learner-generated drawings in each session. This is under what was stated by Huijsmans et al. (2021) that MLD students could improve cognitive abilities over time. Thus, the implication of the results of this study is to contribute empirical evidence and findings that MLD students at the elementary school level can generate mathematical ideas in the form of drawings and show a better tendency to change drawings as time passes between sessions. Students' learner-generated drawings reflect students' conceptual understanding of integer operations (Natsheh \& Karsenty, 2014). Meanwhile, changes in the learner-generated drawings of MLD students indicate the development of student understanding towards a better direction in interpreting symbolic representations into visual representations. (Al-Mutawah et al., 2019; Barmby et al., 2012; Martin, 2008). Further research is recommended to use mixed- 
methods to provide a numerical measurement of the significance of the effect of tasks in the form of open number sentences questions on adding and subtracting integer operations to the types of drawings and learner-generated drawings changes of MLD students.

\section{Conclusion}

MLD students at the elementary school level can produce varied and fairly consistent drawings. They can provide logical answers representing adding and subtracting integers from solving open numeric sentence questions. The types of learner-generated drawings by MLD students: discrete objects with single and double sets of objects; transition from objects to number lines with number sequence; continuous number lines with empty number lines; number sentences with vertical and horizontal sentences; and other in the form of answer in the box only which only answers the result; emphasis on the plus, minus, or negative sign, and blank by emphasizing the sign (cross or circle). Changes in the learner-generated drawings of MLD students are seen between sessions; this change leads to improvements in learner-generated drawings in representing symbols visually.

\section{Acknowledgment}

The author would like to thank all parties involved for helping and facilitating this research to be completed correctly and on time, especially to the Universitas Muhammadiyah Sidoarjo and SDN Kalitengah 2 Tanggulangin Sidoarjo.

\section{Conflicts of Interest}

The author declares that no conflict of interest regarding the publication of this manuscript. In addition, the ethical issues, including plagiarism, misconduct, data fabrication and/or falsification, double publication and/or submission, and redundancies.

\section{References}

Al-Mutawah, M. A., Thomas, R., Eid, A., Mahmoud, E. Y., \& Fateel, M. J. (2019). Conceptual understanding, procedural knowledge and problem-solving skills in mathematics: High school graduates work analysis and standpoints. International Journal of Education and Practice, 7(3), 258-273. https://doi.org/10.18488/journal.61.2019.73.258.273

Barmby, P., Bolden, D., Raine, S., \& Thompson, L. (2012). Developing the use of visual representations in the primary classroom. In The professional development conference ( $\mathrm{p}$. 67). Durham University.

Bishop, Jessica P., Lamb, L. L., Philipp, R. A., Whitacre, I., \& Schappelle, B. P. (2018). Students' thinking about integer open number sentences. In Research in Mathematics Education, (pp. 47-71). Springer. https://doi.org/10.1007/978-3-319-90692-8 3

Bishop, Jessica Pierson, Lamb, L. L., Philipp, R. A., Whitacre, I., \& Schappelle, B. P. (2014). Using order to reason about negative numbers: The case of violet. Educational Studies in Mathematics, 86(1), 39-59. https://doi.org/10.1007/s10649-013-9519-x 
Bofferding, L. (2014). Negative integer understanding: Characterizing first graders' mental models. Journal for Research in Mathematics Education, 45(2), 194-245. https://doi.org/10.5951/jresematheduc.45.2.0194

Bofferding, L., \& Wessman-Enzinger, N. (2017). Subtraction involving negative numbers: Connecting to whole number reasoning. Mathematics Enthusiast, 14(1), 241-262. https://doi.org/10.54870/1551-3440.1396

Bryant, D. P., Bryant, B. R., Dougherty, B., Roberts, G., Pfannenstiel, K. H., \& Lee, J. (2020). Mathematics performance on integers of students with mathematics difficulties. Journal of Mathematical Behavior, 58, Article 100776. https://doi.org/10.1016/j.jmathb.2020.100776

Carvalho, R., \& Ponte, J. P. da. (2016). Student strategies and errors in mental computation with rational numbers in open number sentences. CERME9 - Ninth Congress of the European Society for Research in Mathematics Education, 245-251, Article 01281840. https://doi.org/10.13140/RG.2.1.3947.4325

Cetin, H. (2019). Explaining the concept and operations of integer in primary school mathematics teaching: Opposite model sample. Universal Journal of Educational Research, 7(2), 365-370. https://doi.org/10.13189/ujer.2019.070208

Cresswell, J. W. (2012). Planning, conducting, and evaluating quantitative and qualitative research. Educational Research, 10, 1-12.

Fuadiah, N. F., Suryadi, D., \& Turmudi. (2019). Teaching and learning activities in classroom and their impact on student misunderstanding: A case study on negative integers. International Journal of Instruction, 12(1), 407-424. https://doi.org/10.29333/iji.2019.12127a

Gulkilik, H., Moyer-Packenham, P. S., Ugurlu, H. H., \& Yuruk, N. (2020). Characterizing the growth of one student's mathematical understanding in a multi-representational learning environment. Journal of Mathematical Behavior, 58, Article 100756. https://doi.org/10.1016/j.jmathb.2020.100756

Hanich, L. B., Jordan, N. C., Kaplan, D., \& Dick, J. (2001). Performance across different areas of mathematical cognition in children with learning difficulties. Journal of Educational Psychology, 93(3), 615-626. https://doi.org/10.1037/0022-0663.93.3.615

Hoogland, K., Koning, J. De, Bakker, A., Pepin, B. E. U., \& Gravemeijer, K. (2018). Changing representation in contextual mathematical problems from descriptive to depictive: The effect on students' performance. Studies in Educational Evaluation, 58, 122-131. https://doi.org/10.1016/j.stueduc.2018.06.004

Huijsmans, M. D. E., Kleemans, T., \& Kroesbergen, E. H. (2021). The cognitive profiles for different samples of mathematical learning difficulties and their similarity to typical development: Evidence from a longitudinal study. Journal of Experimental Child Psychology, 214, Article 105288. https://doi.org/10.1016/j.jecp.2021.105288

Karagiannakis, G., Baccaglini-Frank, A., \& Papadatos, Y. (2014). Mathematical learning difficulties subtypes classification. Frontiers in Human Neuroscience, 8, 1-5, Article 57. https://doi.org/10.3389/fnhum.2014.00057

Lamb, L. L., Bishop, J., Philipp, R. A., Whitacre, I., \& Schappelle, B. P. (2016). The relationship between flexibility and student performance on open number sentences with integers. Proceedings of the 38th Annual Meeting of the North American Chapter of the International Group for the Psychology of Mathematics Education, 171-178. https://eric.ed.gov/?id=ED583651

Lewis, K. E., Sweeney, G., Thompson, G. M., \& Adler, R. M. (2020). Integer number sense and notation: A case study of a student with a mathematics learning disability. Journal of $\begin{array}{llll}\text { Mathematical Behavior, } & \text { 59, Article }\end{array}$ https://doi.org/10.1016/j.jmathb.2020.100797 
Luit, J. E. H. van. (2019). Diagnostics of dyscalculia. In International Handbook of Mathematical Learning Difficulties: From the Laboratory to the Classroom (pp. 653668). https://doi.org/10.1007/978-3-319-97148-3

Martin, L. C. (2008). Folding back and the dynamical growth of mathematical understanding: Elaborating the Pirie-Kieren Theory. Journal of Mathematical Behavior, 27(1), 64-85. https://doi.org/10.1016/j.jmathb.2008.04.001

Miles, M. B., Huberman, A. M., \& Saldana, J. (2014). Qualitative data analysis: A methods sourcebook (third edit). SAGE Publications, Inc.

Natsheh, I., \& Karsenty, R. (2014). Exploring the potential role of visual reasoning tasks among inexperienced solvers. ZDM - International Journal on Mathematics Education, 46(1), 109-122. https://doi.org/10.1007/s11858-013-0551-1

Saxe, G. B., Diakow, R., \& Gearhart, M. (2013). Towards curricular coherence in integers and fractions: A study of the efficacy of a lesson sequence that uses the number line as the principal representational context. ZDM - International Journal on Mathematics Education, 45(3), 343-364. https://doi.org/10.1007/s11858-012-0466-2

Schmidgall, S. P., Eitel, A., \& Scheiter, K. (2019). Why do learners who draw perform well? Investigating the role of visualization, generation and externalization in learner-generated drawing. Learning and Instruction, 60, 138-153. https://doi.org/10.1016/j.learninstruc.2018.01.006

Shanty, N. O. (2016). Investigating students' development of learning integer concept and integer addition. Journal on Mathematics Education, 7(2), 57-72. https://doi.org/10.22342/jme.7.2.3538.57-72

Siegler, R. S., \& Crowley, K. (1991). The microgenetic method: A direct means for studying cognitive development. American Psychologist, 46(6), 606-620. https://doi.org/10.1037/0003-066X.46.6.606

Stephan, M., \& Akyuz, D. (2015). A proposed instructional theory for integer addition and subtraction. National Council of Teachers of Mathematics, 43(4), 428-464. https://doi.org/10.5951/jresematheduc.43.4.0428

Van Meter, P., \& Garner, J. (2005). The promise and practice of learner-generated drawing: Literature review and synthesis. Educational Psychology Review, 17(4), 285-325. https://doi.org/10.1007/s10648-005-8136-3

Wessman-Enzinger, N. M. (2019). Grade 5 children's drawings for integer addition and subtraction open number sentences. Journal of Mathematical Behavior, 53, 105-128. https://doi.org/10.1016/j.jmathb.2018.03.010

Wessman-Enzinger, N. M., \& Mooney, E. S. (2014). Making sense of integers through storytelling. Mathematics Teaching in the Middle School, 1(1), 53-59. https://doi.org/10.5951/TCM.1.1.0053

Wessman-Enzinger, N. M., \& Mooney, E. S. (2019). Conceptual models for integer addition and subtraction. International Journal of Mathematical Education in Science and Technology, 52(3), 349-376. https://doi.org/10.1080/0020739X.2019.1685136 